\title{
Influência social na vida familiar: grupo étnico e relações interculturais ${ }^{1}$
}

\author{
Edson Alves de Souza Filho \\ Universidade Federal do Rio de Janeiro, Rio de Janeiro-RJ, Brasil \\ Angel Beldarrain-Durandegui ${ }^{2}$ \\ Loughborough University, Leicestershire, United Kingdon
}

\begin{abstract}
Resumo: Analisamos lembranças de jovens judeus e não judeus para inferir padrões de influência social adotados por pais e antepassados. Supomos que o modo de influenciar entre os judeus esteja relacionado à busca de autonomia, diferenciação e delimitação de fronteiras interindividuais/intergrupais, enquanto entre os não judeus seja o contrário. Os jovens eram estudantes de ensino médio de duas escolas privadas. Com os sobrenomes, formamos subgrupos de asquenazins (judeus alemães), asquenazins/sefaradins (judeus ibéricos), judeus/não judeus e não judeus. Eles relataram lembranças de pais e antepassados, recuando até a $5^{\text {a }}$ geração; simularam autoapresentação para alguém de outra religião; indicaram lugares onde viveriam no exterior; e mencionaram dez sobrenomes fora das suas famílias. Os modelos de influência dos judeus enfatizaram aspectos individuais/grupais da vida familiar, os dos não judeus, relações interindividuais. A autoapresentação para outrem dos judeus mostrou focalização nos aspectos grupais de si e de outrem, enquanto a dos não judeus, cortesia/cumprimento.
\end{abstract}

Palavras-chave: relações familiares, grupos sociais, história social.

\section{Social influence in family life: ethnic group and intercultural relations}

\begin{abstract}
Remembrances of young Jews and non-Jews were analyzed to infer patterns of social influence adopted by their parents and ancestors. We suppose that the ways of influencing among Jews is related to a search of autonomy, differentiation and demarcation of interindividual/intergroup boundaries, which is the opposite among non-Jews. The participants were students from two private high schools. Subgroups were formed according to surnames: Ashkenazim (German Jews), Ashkenazim/Sephardim (Iberian Jews), Jews/Non-Jews and Non-Jews. They reported remembrances of parents and ancestors, going back until the $5^{\text {th }}$ generation; simulated a self-introduction to a person with a different religious background; indicated places abroad where they would live; and mentioned ten surnames other than their families'. Influence models of Jewish students emphasized individual and group aspects of family life, while non-Jews emphasized inter-individual relationships. The Jews' self-introduction to others revealed emphasis on their own and others' group aspects, while non-Jews emphasized courtesy/politeness.
\end{abstract}

Keywords: family relations, social groups, social history.

\section{Influencia social en la vida familiar: grupo étnico y relaciones interculturales}

Resumen: Analizamos recuerdos de jóvenes judíos y no-judíos para inferir modelos de influencia social adoptados por sus padres y antepasados. Suponemos que el modo de influenciar entre los judíos esté relacionado con búsqueda de autonomía, diferenciación y delimitación de fronteras interindividuales/intergrupales, al contrario que entre los no-judíos. Los jóvenes eran alumnos de enseñanza secundaria de dos escuelas privadas. Con los apellidos formamos subgrupos ashkenazitas (judíos alemanes), ashkenazitas/sefarditas (judíos ibéricos), judíos/no-judíos y no-judíos. Ellos relataron recuerdos de padres y antepasados, retrocediendo hasta la quinta generación; simularon auto-presentación a alguien de otra religión; indicaron lugares del extranjero donde vivirían; y mencionaron diez apellidos que no fueran de su familia. Los modelos de influencia de los judíos enfatizaron aspectos individuales/grupales de la vida familiar, los de no-judíos relaciones interindividuales. La autopresentación de los judíos para otro mostró enfoque en aspectos grupales de si mismo y del otro, y el de los no-judíos cortesía/buena educación.

Palabras clave: relaciones familiares, grupos sociales, historia social.

O estudo dos padrões socioculturais, a partir de uma ótica psicossocial, tornou-se um objeto acadêmico. Sabemos que as sociedades dispõem de inúmeros grupos socioculturais,

1 Apoio: FAPERJ. Os autores agradecem a colaboração de Priscilla Reismann, bolsista de Iniciação Científica do CNPq e à FAPERJ, pela bolsa de apoio técnico concedida ao segundo autor. Esse texto foi revisado seguindo o Acordo Ortográfico da Língua Portuguesa (1990), em vigor a partir de $1^{\circ}$ de janeiro de 2009.

2 Endereço para correspondência:

Prof. Dr. Edson Alves de Souza Filho. Universidade Federal do Rio de janeiro. Programa de Pós-graduação em Psicologia. Av. Pasteur, 250, Campus da Praia Vermelha. CEP 22.290-240. Urca, Rio de Janeiro, RJ. E-mail: edsouzafilho@gmail.com sobretudo da situação moderna em diante. Contudo, em termos psicossociais, podemos considerar que existem grupos majoritários e minoritários (Lewin, 1948). Podemos considerar como grupo étnico minoritário, no sentido demográfico, aqueles de tamanho menor numa dada sociedade, seja no sentido da valorização, reconhecimento e poder social considerados inferiores aos obtidos por demais grupos existentes, na mesma sociedade ou no conjunto dela. Segundo Lewin (1948), nos grupos étnicos minoritários, existem forças centrífugas que impulsionam os seus membros para fora dos mesmos, em função da sua menor presença e/ou valorização relativa na sociedade, facilitando a ocorrência de casamentos mistos que podem implicar em diluição do grupo. A fim de 
evitar isso, a luta para preservar os padrões socioculturais em ambientes sociais de competição costuma estar presente também na família. No caso dos grupos étnicos minoritários de longa duração histórica, ou seja, com acúmulo de experiências de relações interculturais, existem formas milenares de organização social que afetam as interações no plano familiar. Contudo, a possibilidade de desintegração dos grupos minoritários é uma ameaça real e contínua, a ser enfrentada de alguma maneira. Poderíamos dizer que parte dos esforços dos grupos étnicos minoritários para mantê-los vivos e coesos depende do que ocorre no âmbito das famílias em termos de influência social.

As teorias psicossociais têm enfatizado diferentes variáveis de influência social, dando destaque para aquelas relacionadas ao poder exercido sobre os alvos de influência (Moscovici, 1979). Ao lado disso, alguns autores verificaram a importância de retóricas usadas por sujeitos que pretendem influenciar, comunicando consistência e flexibilidade, entre outras variáveis (Moscovici, 1979). Ou seja, independente do mérito da proposta/mensagem, o modo de apresentá-la, indicando coerência, não contradição, além de sinal de certeza, vontade de manter um ponto de vista em relação ao qual alguém está comprometido, direcionado, pode ter um efeito de influência social (Moscovici, 1979). Porém, como as mensagens circulam atualmente de modo tão intenso e extenso, a importância do conflito e de sua negociação cresce. Nesse sentido, não é suficiente "ter razão" ou saber ouvir o outro, mas, sobretudo, como negociar com ele. A flexibilidade, tal como foi estudada, seria a postura do sujeito que pretende influenciar, além de manter sua posição, levar em conta as mensagens/propostas do outro em confronto explícito ou implícito. No caso de grupos sociais minoritários, que são menos valorizados fora deles, quando não ameaçados de sobrevivência, o esforço para que os processos de influência ocorridos no seu interior sejam os mais suaves possíveis vai tornar-se necessário, sobretudo durante a formação básica, da infância à juventude, fazendo com que se faça uso o menos possível de recursos de poder, possivelmente, para evitar que a influência seja mais em função de submissão ao poder do educador do que da avaliação individual do mérito do que se pretende influenciar. Ao lado disso, supondo que os judeus circulam boa parte do tempo em ambientes não judeus, onde podem ser influenciados por outros grupos culturais e adotar a perspectiva destes últimos, frequentemente antissemitas, a melhor maneira de evitar isso é garantir a liberdade de pensamento e atitude positiva em relação ao próprio grupo e familiares; este último objetivo também buscado por outros grupos ameaçados de desvalorização social (Szymanski, 2006). Estudos comparativos interculturais recentes indicaram a tendência entre judeus de favorecer a autonomia e independência individual nas relações familiares (Somech, 2000; Peleg-Popko \& Nahhas, 2003). Nesse sentido, Kelman (1958) verificou que o processo de internalização era mais duradouro quando o alvo de influência avaliava a mensagem/proposta segundo seu ponto de vista, se comparado aos processos de conformismo e identificação que seriam mais relacionados aos efeitos do poder de quem está influenciando e aos benefícios individuais imediatos de quem está sendo influenciado.

No âmbito da família, as relações costumam ser pautadas por vários padrões de influência social, segundo os grupos socioculturais, ressaltando aspectos que poderíamos definir como de relações básicas, com ênfase em cuidados dispensados aos filhos/netos, incluindo afetos, atenções, proteções e cuidados relativos à escolarização, entre outras; relações interpessoais, referentes às interações que visam às vivências comuns de situação de lazer e diversão, num clima que busca a igualdade; as relações de poder, em que se incluem pressões suaves ou duras dos pais/avós sobre os membros da família para seguir as suas metas. Mas também existem formas de influência de modelos sociais indiretos, relativos aos pais e a outros familiares considerados como indivíduos com comportamentos/mentalidades a serem admirados/seguidos, seja no sentido de um "culto à personalidade" a partir de valores morais/éticos gerais, seja no sentido de informações a respeito de ações/resultados obtidos por alguém individualmente, a serem adotados ou não por parte do aprendiz, dependendo mais da sua decisão.

Poderíamos considerar que os três tipos de influência relacionais acima referidos (básica, interpessoal, poder) estejam mais associados a formas de poder, uma vez que objetivamente os pais/educadores que os adotam dispõem de poder explícito ou implícito sobre os filhos/netos. Já a influência, por meio de modelos individuais de conduta, poderia ser aproximada da influência social minoritária (Moscovici, 1979), uma vez que está retoricamente mais associada à comunicação de qualidades individuais daquele que tenta influenciar, formas de demonstração de ações/resultados, eventualmente levando em conta na negociação aspectos da perspectiva do outro. É como se eles estivessem persuadindo/ dissuadindo o alvo da influência sem uso do poder, mas, sobretudo, a partir da sua capacidade de fazer-se compreender em termos lógicos e formais ou de se comportar segundo esses princípios, o que exigiria a liberdade de escolher de filhos/netos.

Portanto, nosso propósito teórico foi analisar as descrições sobre os parentes por parte de jovens brasileiros para inferir modos de influenciar adotados no âmbito familiar à luz de teorias de influência social, incluindo grupos judeus e não judeus. A escolha dos judeus nos permitiria observar, de modo sistemático e comparativo, alguns aspectos já descritos por historiadores a respeito da sua capacidade de sobrevivência grupal (Goldberg \& Rayner, 1989), bem como de ter adotado modelos baseados na persuasão "informativa", desde antes da modernidade (Maimonides, 1190/1956).

Sabemos que os judeus foram expulsos de Israel no início da era cristã, iniciando a chamada diáspora ou dispersão do grupo no mundo, sobretudo em várias partes da Europa e norte da África. Posteriormente, eles foram expulsos da Espanha e, logo em seguida, de Portugal, entre outros episódios marcantes. Assim, a situação histórica dos judeus 
no Ocidente tornou-se problemática em termos políticos. A negociação intergrupal de alto nível, de modo a facilitar a sobrevivência do grupo, não foi suficiente muitas vezes para impedir os ataques externos, obrigando a adoção de formas de educação específicas para preparar filhos/netos para a migração, para a sobrevivência individual/grupal. Em consequência, muitos membros individuais de uma mesma família tiveram de viver em países diferentes, implicando em isolamento individual/grupal prolongado. Para tanto, a ideia de história do grupo em termos de lembranças e traços socioculturais vai ser crucial para a sua sobrevivência. Sabemos que a memória social é construída, no sentido de que o indivíduo que relata um material existencial, mesmo sendo o produto de síntese individual, reflete situações sociais e históricas vividas que são resultados de influências sociais. À luz da literatura existente, contudo, foi possível anteciparmos algumas tendências psicossociais.

Lembraríamos que, ao longo da história da diáspora, o modo de manifestação do antissemitismo, nos vários contextos, acabou alterando diferencialmente a vida interna das comunidades judaicas, inclusive no âmbito familiar e individual (Goldberg \& Rayner, 1989). Sabemos que os judeus viveram quase 1.500 anos na Península Ibérica, bem como em outras partes da Europa, como o contingente que se assentou na Alemanha - um dos maiores e mais prolongados -, a partir dos quais se constituíram os sefaradins e asquenazins, respectivamente, com línguas e práticas bastante diferenciadas, apesar de partilharem o judaísmo (Goldberg \& Rayner, 1989). Contudo, o grupo asquenazi foi historicamente o que mais sobreviveu em termos demográficos, uma vez que os sefaradins sofreram o longo período da Inquisição seguido pelo Holocausto, do que os asquenazins, da Europa Central e Oriental, se livraram parcialmente (Goldberg \& Rayner, 1989). Tal quadro histórico implicou em diferenças socioculturais importantes entre os dois grupos. Enquanto na Península Ibérica o longo empreendimento inquisitorial gerou um perfil judeu mais aberto às ideias contidas na modernidade: estiveram entre os primeiros livre-pensadores e participaram dos movimentos republicanos e liberais (Novinsky, 1992); na Europa Central, por sua vez, houve um isolamento prolongado nos guetos que, se trouxe um bem-estar individual em decorrência da solidariedade e estabilização desfrutadas, também aumentou a tradição (Lewin, 1948) e a maior fixação de papéis sociais no interior do grupo. Ou seja, o tipo de tortura moral e psicológica sofrida pelo judeu na Inquisição acarretou a necessidade de alguém com uma psicologia mais individual, e que busca a adaptação social, tendo em vista a relativa solidão que se seguiu à dissolução pública do grupo, sobretudo após a expulsão da Espanha, práticas que foram adotadas por asquenazins bem mais tarde.

Posteriormente à Segunda Guerra Mundial, com a migração para as Américas de muitos judeus europeus, sefaradins e asquenazins começaram a se casar e a formar famílias mistas. A vida familiar judaica se constitui em foco central para a socialização e experiência básica de rituais religiosos da infância até o final da vida, por meio da fruição de alimentos com significado identitário (Friedman, Friedlander, \& Blustein, 2005), entre outros, além da própria diferenciação por contraste em que as particularidades do grupo são ressaltadas. Parte da sobrevivência do judaísmo derivaria da formação de indivíduos, segundo a aprendizagem de regras morais e éticas particulares que tenderia a fortalecer a autonomia individual/familiar, apesar de ênfases diferenciadas, segundo os grupos formados a partir dos assentamentos ibéricos ou alemães. Tais processos de socialização caracterizar-se-iam por pronunciada individuação, produto de um tipo de vivência que procura estabelecer diferenças interindividuais na família e a presença de autoridades parentais que oferecem amparo e dispositivos de troca que não sobrecarregam o indivíduo com exigências/pressões. Esta preparação incluiria a busca autônoma de oportunidades de negócios e a frequente recusa de conformismo, o que teria permitido a liberdade de opinião e ação e a sobrevivência do grupo.

No que toca às diferenciações esperadas no interior da comunidade judaica (Scliar, 1994), formadas a partir dos vários tipos de casamentos, podemos imaginar que a existência de um maior número de asquenazins aumente a perda de especificidades dos demais, tendo em vista a relativa invisibilidade social de sefaradins.

Já os estudos existentes sobre as relações familiares entre brasileiros, que são católicos em maioria, indicaram maior ênfase nas relações interpessoais e afetivas e uma tendência de prevalência da entidade família sobre os seus membros individuais (Gonçalves, 2005; Silva Júnior \& Andrade, 2007), o que tem sobrevivido ao declínio do patriarcado nos ambientes urbanos, cabendo mais estudos psicossociais. Ou seja, as teorias de influência social oferecem uma oportunidade relativamente pouco ou nada explorada por parte de psicólogos sociais para estudar as relações familiares na sociedade brasileira. Nesse sentido, supomos que, no ambiente de classe média atualmente, ocorra um declínio de relações familiares baseadas no poder explícito entre seus membros. Apesar disso, supomos que outras formas de realizar poder tenham sido construídas no âmbito das famílias, implicando em estratégias e modos de influência social distintos dos grupos socioculturais em função de objetivos psicossociais a serem mais conhecidos.

Nesse contexto, o objetivo principal deste trabalho foi inferir modos de exercer influência familiar de grupos com padrões socioculturais diferentes, segundo a perspectiva dos jovens, que são objeto de influência social nesses ambientes. A nossa pergunta de partida foi a respeito da influência de padrões socioculturais sobre os filhos/netos oriundos desses grupos. Em seguida, pretendíamos averiguar os possíveis desdobramentos desses padrões socioculturais familiares, no modo de vivenciar ou interagir com indivíduos de outros grupos socioculturais. Enfim, uma terceira questão foi saber se os padrões socioculturais adquiridos no âmbito das relações familiares poderiam afetar na possível escolha de países para viver, em um momento histórico da globalização. 
Assim, pretendemos inferir, a partir de relato de jovens pertencentes à comunidade judaica do Rio de Janeiro os padrões de influência social adotados em diferentes tipos de casamentos encontrados no interior da mesma, em comparação com não judeus.

\section{Método}

Trata-se de um estudo retrospectivo, trabalhando com dados já existentes, de uma pesquisa cujos dados foram coletados em 1999, em que foi assegurado o direito de participar ou não da pesquisa.

\section{Participantes}

Participaram dessa pesquisa 77 jovens, com idade média de 16,3 anos ( $\mathrm{DP}=0,75)$, de ambos os sexos (sendo $51,4 \%$ do sexo masculino e $48 \%$ feminino), estudantes de ensino médio de uma escola judaica no Rio de Janeiro e 73 jovens (média de idade $=15,7 ; \mathrm{DP}=0,85$ ), de ambos os sexos ( $52 \%$ do sexo masculino e $47,9 \%$ feminino), de uma escola privada com maior presença de católicos (cerca de 70\%), incluídos aqui a título comparativo.

\section{Instrumento e Procedimento}

Solicitamos que eles indicassem (a) os sobrenomes que se lembravam dos seus antepassados, recuando o máximo possível na história dos ramos patrilinear e matrilinear; (b) as lembranças sobre os mesmos parentes e suas identidades religiosas/étnicas; (c) as autoapresentações simuladas para uma pessoa de religião budista ou muçulmana (no caso dos jovens de origem cristã); (d) os países e cidades em que viveriam fora do Brasil, caso pudessem; (e) dez sobrenomes existentes no Brasil, mas não pertencentes à sua família; (f) informações sobre a profissão e o nível de escolaridade de pai e mãe; profissão que gostariam de exercer e o nível máximo de estudos pretendido, além de idade, sexo e participação em associações.

Para verificarmos as possíveis influências de pais/avós e antepassados sobre os jovens, seria necessário observar sistematicamente os conteúdos mencionados em termos de sobrenomes e lembranças por parte destes últimos a respeito dos seus familiares, comparando os grupos socioculturais. Nossa suposição foi de que a influência familiar estivesse relacionada à ênfase em três tipos de autoridade e relação social, tal como inferidas dos relatos de memória dos jovens: individual, relacional interindividual (básica, interpessoal, poder), grupo social, sociedade, entre outras. A influência étnica minoritária, segundo o modelo teórico exposto, seria mais centrada na busca de independência/autonomia individual do jovem e explicitação constante de contrastes socioculturais intergrupais na sociedade. Já influência étnica majoritária, por sua vez, seria mais centrada na relação familiar de interdependência (básica, interpessoal), assim como em menor explicitação do seu próprio grupo, possivelmente considerado como mais geral na sociedade.

Ademais, poderíamos verificar a possível influência familiar/grupo cultural, segundo os modelos de influência mencionados a partir de repercussões na vida cotidiana dos jovens em termos de relações interculturais, incluindo relacionamento com estrangeiros, países escolhidos para viver e percepções sobre a presença do próprio grupo de pertença na sociedade em termos de sobrenomes. Outros itens do instrumento usado na pesquisa não serão relatados aqui em função da limitação do espaço.

\section{Análise de dados}

Para analisarmos os dados patronímicos no caso dos judeus, trabalhamos para identificar o subgrupo étnicoreligioso; depois, organizamos os grupos de casamentos como famílias compostas por asquenazi com asquenazi $(\mathrm{AxA})(\mathrm{n}=35)$, asquenazi com sefaradi $(\mathrm{AxS})(\mathrm{n}=20)$, judeu e não judeu $(\mathrm{JxNJ})(\mathrm{n}=22)$. É bom notar que a maioria dos participantes não judeus mencionou predominantemente sobrenomes ibéricos em suas próprias famílias. Em segui$\mathrm{da}$, as respostas dos jovens foram segmentadas em temas os quais, independente de sua orientação favorável/desfavorável, foram reunidos em categorias e ordenados em tabelas de frequência e percentagem para comparação. Foi possível organizar os dados simbólicos de modo a detectar tendências socioculturais no interior do grupo e em relação a outros resultados de pesquisa com grupos não judeus de meios sociais próximos. A análise psicossocial dos dados foi feita em duas etapas: primeiro, descrever qualitativamente os temas usados para relatar lembranças sobre os familiares e, em seguida, comparar os grupos observados para verificar similaridades e diferenças intergrupais, por meio de análise estatística (Qui-quadrado).

Em seguida, fizemos um agrupamento de temas segundo o recorte pretendido, conforme se segue: indivíduo: personalidade global, cognição, realização profissional, valor do trabalho, formação de parentes, realização subjetiva; relações básicas: afeto sentido/recebido, proteção/cuidado, formação do sujeito, presença/ausência; relações interpessoais: comportamento social, amizade/comunidade, satisfação/diversão, expressão/comunicação; relações de poder: família idealização, interação/papel social/contexto, exige respeito/ severo/rígido, permissivo/recompensador; grupo cultural: identidade étnica/folclore/religião, traço físico/concreto, família solidariedade/ampliada; sociedade conformidade: bem comportado/desviante, valor moral/ético geral; sociedade mudança: evento sociopolítico, reconhecimento social, moderno/flexível; vida/morte.

Somamos as lembranças, em termos de unidades de análise temáticas, e dividimos pelo número de participantes de cada subgrupo que apresentaram as seguintes médias de temas lembrados: $\mathrm{AxA}=9,62 ; \mathrm{AxS}=12,44 ; \mathrm{JxNJ}=9,9$; 
$\mathrm{NJ}=6$,52. Se retirarmos do cômputo as "não respostas", os judeus ficam com a média 10,1 e os não judeus, com 5,56.

\section{Resultados e Discussão}

Abaixo apresentamos os temas encontrados para descrever lembranças/memórias de antepassados sobre familiares de todos os jovens que participaram da pesquisa, sendo que junto de cada frase existem notações sobre sexo, idade e tipo de família a que eles pertencem:

1) Personalidade global: quando foram lembrados traços, definições e narrações que procuraram indicar uma disposição de personalidade, considerados como mais permanentes, globais e essenciais, incluindo aspectos internos, subjetivos, como estados mentais/psíquicos, assim como metas valorativas terminais ou adiadas as quais não precisam de outra pessoa para se realizar: "Orgulhoso, forte" (M., 17, AxA); "Determinada, batalhadora" (F., 16, AxS), "Sério" (F., 16, JxNJ); "Frio" (F, 16, EC);

2) Comportamento social: quando foram recordados comportamentos situacionais sociais que indicaram interações ou potenciais para tipos de ação prática imediata que buscam se conformar ou não a normas interpessoais, sem procurar entender o padrão ou modelo interno que os orientam, mas apenas aspectos externos e manifestos do convívio: "Muito gentil" (M., 16, AxS); "Simpatia" (M., 16, JxNJ); "Pessoa meiga" (M, 16, EC);

3) Cognição: quando os parentes foram descritos a partir de aspectos cognitivos e de conhecimentos ligados à vida intelectual, resolução de tarefas ou expressão de estilos mentais de organizar conteúdos psicológicos e sociais: "Inteligente" (M., 16, AxA); "Curiosidade" (F., 17, JxNJ);

4) Identidade étnica/folclore/religião/cultura: quando foram registradas ligações do parente com contexto social, local e grupal, a partir de práticas e marcas identificatórias ou país de origem: "Meio judeus, meio cristãos, meio italianos" (M., 17, JxNJ); "Nasceu em Tanger no Marrocos" (F., 17, AxS); "Sotaque de polonesa puxado" (F., 17, AxA); "Portuguesa e espanhola, adora fazer comida" (F, 15, EC);

5) Afeto recebido/sentido: quando foram descritas experiências de receber ou sentir diferentes afetos e sentimentos com relação a parentes: "Muito amor, carinho" (F., 16, JxNJ); "Amo todos os membros da minha família" (F., 16, AxA); "Rejeição" (M, 15, EC); "Amava de verdade sua família" (M., 17, AxS);

6) Proteção/cuidado: quando foi descrito um cuidado/ proteção, dedicado/recebido pelo sujeito ou alguém da família, independentemente da fase da vida ou tipo de atividade correspondente, apesar de predominarem aqueles referentes à infância e adolescência dispensados por mães e pais em relação a filhos e netos: "Sempre me protege e quer sempre o melhor para mim" (F., 16, AxA); "adorava cuidar dos netos e bisnetos" (F., 17, AxA); "Tutor" (M., $18, \mathrm{AxS})$; “Água na cama à noite" (M, 16, EC);

7) Vida/morte: quando foram relatados aspectos ligados tanto à vida/vitalidade/saúde, quanto à morbidez/decadência física/morte: "Vontade de viver" (F., 16, AxA); "Tá muito doente" (F., 17, AxS); "Morreu no aniversário de 15 da minha mãe" (F., 16, JxNJ); "Já não está entre nós" (M, 16, EC);

8) Interação/papel social/contexto: quando foram relatadas experiências da vida cotidiana e encontros interpessoais, entre dois ou mais familiares, ressaltando papéis sociais e/ou pertencimento familiar: "Visitas" (F., 17, AxA); "Ótimo papel de avó, porém péssimo de mãe" (M., 17, AxS); "Todo domingo me levava à churrascaria para almoçar" (M., 16, JxNJ);

9) Realização profissional/material: quando o parente foi apresentado a partir de sua profissão exercida, assim como de sucessos decorrentes tanto do âmbito do trabalho, quanto do remunerativo: "Era muito rico" (F., 15, AxA); "Dentista protético" (M., 17, AxS); "Bem-sucedida profissionalmente" (F., 16, JxNJ); "Tinha um armazém, pertencia à alta sociedade" (M, 18, EC);

10) Presença/ausência: quando foi mencionado um parente ausente, distante ou presente na vida do sujeito, sem outros comentários sobre o tipo de experiência comum ou qualificação da mesma: "Presente em tudo na minha vida” (F., 17, JxNJ); “Nada, falta” (M., 17, JxNJ);

11) Valores morais/éticos gerais: quando o parente foi descrito a partir de princípios morais/éticos gerais como valores terminais supraindividuais/grupais, como humanismo, altruísmo, justiça, responsabilidade, equidade, verdade, honestidade, simplicidade, respeito, entre outros: "Honesto" (M., 18, AxA); "Humanista" (F., 16, $\mathrm{JxNJ}$;

12) Satisfação/diversão: quando foram referidas atividades específicas de lazer e diversão, como esporte, arte, entre outros, assim como de ausência das mesmas e desprazeres relacionados com o modo de vida levado: "Xadrez (...) dominó" (F., 17, AxA); "Passeio às terças" (M., 16, AxA); "Sofrimento" (M., 16, JxNJ); "Flamenguista" (M, 15, EC);

13) Valor trabalho: quando foi ressaltado o trabalho enquanto prática como valor em si, sem mencioná-lo como realização de um sujeito, nem o tipo de trabalho: "Trabalha muito" (F., 16, SxA); "Homem trabalhador" (M., 19, JxNJ);

14) Família idealização: quando um parente foi definido de modo idealizado, enfatizando apenas os aspectos considerados positivos e superdimensionados: "Melhor pessoa do mundo" (F., 16, JxNJ); "um anjo" (F, 15, EC); 
15) Amizade/comunidade: quando um parente foi considerado como fraternal, amigo ou compartilhando conteúdos com o sujeito ou outros parentes: "Amiga de todas as horas" (M., 16, AxA); "Companheiro" (M., 16, AxS); "Cumplicidade" (F., 16, JxNJ); "Companheiro" (M, 16, EC);

16) Exige respeito/rígido/punição/severo: quando o parente foi considerado seja como alguém que tenta impor ou exige um padrão preestabelecido, seja como quem não leva em conta os pontos de vista do sujeito ou de outros membros da família, sem ou com menos poder: "Não muda o estilo de pensar" (F., 16, AxA); "Mandona" (F., 17, AxS); "Rígido e severo" (M., 16, JxNJ); "Tapa na bunda" (F, 15, EC);

17) Eventos/vivências sociopolíticos: quando foram relacionados à biografia de parentes fatos históricos coletivos marcantes como perseguições de grupos étnicos ou participação política em movimentos sociais: "Um comunista de carteirinha" (M., 16, AxA); "Participou do Holocausto e saiu vivo" (M., 16, AxA); "Também fugira do centro da Europa" (M., 19, JxNJ);

18) Formação de parentes: quando foram referidos episódios, experiências, conhecimentos e processos/práticas, acadêmicas ou não, que formaram parentes: "morou numa biblioteca" (F., 15, AxA); "gostava de estudar, ler e pensar" (F., 17, AxS); "Línguas estrangeiras" (F., 15, SxA); "Vou para o computador" (F, 16, EC);

19) Traços físicos/concretos: quando o parente foi descrito segundo seu aspecto físico externo, sem mencionar como ele lida com isso: "cabelo vermelho, era bonita quando nova" (M., 17, AxA); "Baixinha”(F, 14, EC);

20) Realização subjetiva: quando foram lembradas realizações não materiais, profissionais, mas uma superação pessoal, como atingir estado espiritual/subjetivo de sabedoria, a partir de esforço e caminho individual dentro de algum contexto social definido: "Sabedoria" (M., 17, AxA); "Harmonia" (F, 16, EC);

21) Reconhecimento social: quando foram relatados episódios de realização de parentes com implicação social ou grupal, no sentido de ressaltar sua importância para além da dimensão individual/familiar, mesmo que não existam provas para tal conclusão: "Importante na sociedade" (M., 18, AxA); "Líder" (F., 16, JxNJ);

22) Bem comportado/desviante: quando foram mencionadas condutas consideradas em relação às normas sociais mais consensuais na sociedade, seja para obedecer, seja para desobedecer às mesmas ("a exceção que confirma a regra"): "Muito certinha" (F., 18, JxNJ); "Jamais deixou de pagar os impostos" (M., 19, JxNJ); "Loucura" (M, 16, EC);
23) Família solidariedade/ampliada: quando foi relatado algo sobre um parente não genitor (tio, primo) entre as gerações estudadas: "Irmã de minha bisavó" (M., 18, AxA);

24) Expressão/comunicação: quando foram mencionados ou avaliados os tipos de comunicações/expressões, verbais, corporais ou ambientais, feitas por familiares, ressaltando o lado cênico da interação: "Perua" (M., 17, AxA); "Diz para todos que sou seu namorado" (M., 16, JxNJ); "Pois é!" (F, 15, EC);

25) Formação do sujeito: quando foram descritos episódios, experiências, conhecimentos e processos, práticas, acadêmicos ou não, que formaram o sujeito: "Estuda comigo sempre que preciso" (M., 16, JxNJ); "Me ensina" (F, 15, EC);

26) Moderno/flexível: quando foram lembradas qualidades/posturas ideológicas do parente mais abertas e flexíveis, na hora de se relacionar no âmbito familiar ou fora dele: "Moderna" (F., 17, AxA);

27) Permissivo/laissez-faire: quando o parente foi considerado como alguém que permite que seus filhos/netos e demais façam o que querem, sem impor condições ou regras, negociadas ou preestabelecidas: "Uma pessoa bem mimada" (M., 16, AxA); "Coruja” (F, 15, EC).

Os temas mais lembrados, consensualmente, pelos subgrupos foram: identidade étnica/religiosa, afeto sentido/ recebido, valor do trabalho, morte/vida e evento sociopolítico coletivo. Outros conteúdos obtiveram consensos parciais; AxA e JxNJ (família idealização e traços físicosconcretos); AxA e AxS (interação/contexto) e AxS e JxNJ (personalidade global, exige respeito, não sabe/conhece pouco, reconhecimento social, formação do sujeito). Os temas com maior frequência para cada subgrupo foram: AxA, proteção/cuidado, amizade e realização subjetiva; AxS, realização profissional, formação dos parentes e família ampliada; JxNJ, presença/ausência, morais/éticos, exige respeito, expressão/comunicação, desviante/ bem comportado.

Já a comparação dos subgrupos em termos dos temas agrupados, conforme proposta, indicou as seguintes diferenciações: AxS, indivíduo; AxA, relações básicas; JxNJ, sociedade conformidade. Houve consensos nos seguintes temas agrupados: relações interpessoais, relações de poder, grupo cultural, vida/morte, sociedade mudança. Enfim, a comparação entre judeus e não judeus mostrou diferenciações. Os judeus se destacaram em indivíduo, grupo cultural, vida/morte, sociedade conformidade, sociedade mudança; os não judeus, por sua vez, em relações básicas, relações interpessoais e não sabe/não responde (Tabela 1 e 2). 
Tabela 1

Frequências e percentagens de temas (agrupados) de lembranças de familiares de jovens judeus, segundo os seus subgrupos socioculturais

\begin{tabular}{lcccccc}
\hline \multirow{2}{*}{ Temas } & \multicolumn{3}{c}{$\mathbf{A x A}$} & \multicolumn{2}{c}{ AxS } & \multicolumn{2}{c}{ JxNJ } \\
\cline { 2 - 7 } & $\mathrm{F}$ & $\mathbf{\%}$ & $\mathrm{F}$ & $\mathbf{\%}$ & $\mathrm{F}$ & $\mathbf{\%}$ \\
\hline Indivíduo & 75 & 22,3 & 64 & $\mathbf{2 8 , 5}$ & 46 & 20,9 \\
Relações Básicas & 78 & $\mathbf{2 3 , 2}$ & 36 & 16,0 & 38 & 17,2 \\
Relações Interpessoais & 43 & 12,7 & 25 & 11,1 & 27 & 12,2 \\
Relações de Poder & 40 & 11,9 & 22 & 9,8 & 19 & 8,6 \\
Grupo Cultural & 39 & 11,6 & 24 & 10,7 & 23 & 10,4 \\
Sociedade conformidade & 8 & 2,3 & 8 & 3,5 & 21 & $\mathbf{9 , 5}$ \\
Sociedade mudança & 9 & 2,6 & 10 & 4,4 & 8 & 3,6 \\
Vida/morte & 17 & 5,0 & 15 & 6,6 & 12 & 5,4 \\
Não sabe/não responde & 25 & 7,4 & 20 & 8,9 & 24 & 10,9 \\
Outros & 2 & 0,5 & - & - & 2 & 0,9 \\
Total & 337 & & 224 & & 218 & \\
\hline
\end{tabular}

$\chi^{2}=134,400 ; \mathrm{gl}=9 ; \mathrm{p}<0,0001$

Em relação à autoapresentação, expomos alguns exemplos de temas encontrados: Autoapresentação - pessoal: "que tipo de música eu gosto, que tipo de leitura" (M, 17, EJ); "qual seu nome" (M, 17, EJ); "meu nome é Mariana" (F, 15, EC); Identidade grupal: "que sou brasileira judia" (F, 16, EJ); “quais são suas comidas típicas?” (M, 19, EJ); "Como é sua religião?" (F, 16, EC); Projeto/plano de interação - respeito mútuo: "respeito suas crenças" (F, 16, EJ); "que a força de Alá te proteja!" (M, 16, EC); Criticar/ ensinar/dominar: "Minha religião é melhor do que a sua" (M, 16, EC); Estilo expressivo - cortesia/cumprimento: "oi tudo bem? Prazer em conhecer" (F, 14, EC); Gestos/toques: "me apresentaria através de gestos." (F, 16, EJ).

Com relação à autoapresentação simulada para uma pessoa budista houve, no conjunto, maior frequência de respostas centradas no próprio indivíduo/grupo, em
Tabela 2

Frequências e percentagens de temas (agrupados) de lembranças de jovens judeus e não judeus segundo os seus subgrupos socioculturais

\begin{tabular}{lcccc}
\hline \multirow{2}{*}{\multicolumn{1}{c}{ Temas }} & \multicolumn{2}{c}{ Judeus } & \multicolumn{2}{c}{ Não Judeus } \\
\cline { 2 - 5 } & $\mathbf{F}$ & $\mathbf{\%}$ & $\mathbf{F}$ & $\mathbf{\%}$ \\
\hline Indivíduo & 185 & $\mathbf{2 3 , 7}$ & 86 & 18,0 \\
Relações Básicas & 152 & 19,5 & 117 & $\mathbf{2 4 , 5}$ \\
Relações Interpessoais & 94 & 12,0 & 102 & $\mathbf{2 1 , 4}$ \\
Relações de Poder & 81 & 10,3 & 55 & 11,5 \\
Grupo Cultural & 86 & $\mathbf{1 1 , 0}$ & 21 & 4,4 \\
Sociedade conformidade & 37 & $\mathbf{4 , 7}$ & 14 & 2,9 \\
Sociedade mudança & 28 & $\mathbf{3 , 5 9}$ & - & - \\
Vida/morte & 44 & $\mathbf{5 , 6}$ & 11 & 2,3 \\
Não sabe/não responde & 16 & 2,04 & 70 & $\mathbf{1 4 , 7}$ \\
Outros & 3 & 0,3 & - & - \\
Total & 779 & & 476 & \\
\hline
\end{tabular}

$\chi^{2}=30,369 ; g l=18 ; p<0,0340$.

detrimento de manifestação de intenção de conhecer o outro ou tratar das formas de interação possíveis. Contudo, o reconhecimento da identidade do outro foi observado, indicando postura/sensibilidade intercultural. Os AxA e AxS preferiram centrar-se na sua identidade grupal, em detrimento da individual, tanto ao se autoapresentar, quanto ao procurar conhecer o outro, em que os $\mathrm{AxS}$ se destacaram. Já os JxNJ dividiram-se entre autoapresentação individual/grupal e cortesia/cumprimento. Enfim, os AxA indicaram intenção de manter respeito mútuo e relações interpessoais, em que os JxNJ se sobressaíram. Já os não judeus, ao apresentarem-se para uma pessoa muçulmana, centraram-se na sua identidade individual. Ademais, eles manifestaram temas de respeito mútuo, criticar/ensinar/dominar, cortesia/cumprimento, não responde, língua diferente (Tabela 3 ).

Tabela 3

Frequências e percentagens de formas de autoapresentação de subgrupos judeus para pessoa de religião budista e de não judeus para pessoa de religião muçulmana

\begin{tabular}{|c|c|c|c|c|c|c|c|c|}
\hline \multirow{2}{*}{ Temas } & \multicolumn{2}{|c|}{$\mathbf{A x A}$} & \multicolumn{2}{|c|}{ AxS } & \multicolumn{2}{|c|}{$\mathbf{J x N J}$} & \multicolumn{2}{|c|}{$\mathbf{A x A}$} \\
\hline & $\mathrm{F}$ & $\%$ & $\mathrm{~F}$ & $\%$ & $\mathrm{~F}$ & $\%$ & $\mathrm{~F}$ & $\%$ \\
\hline \multicolumn{9}{|l|}{ Autoapresentação } \\
\hline Individual & 9 & 16,3 & 3 & 9,09 & 5 & 15,1 & 9 & 12,5 \\
\hline Identidade grupal & 16 & 29,0 & 10 & 30,30 & 6 & 18,1 & 1 & 1,3 \\
\hline \multicolumn{9}{|l|}{ Conhecer o outro } \\
\hline Individual & - & - & - & - & - & - & 5 & 6,9 \\
\hline Identidade grupal & 8 & 14,5 & 7 & 21,21 & 5 & 15,1 & 3 & 4,1 \\
\hline \multicolumn{9}{|l|}{ Projeto/Plano de interação } \\
\hline Respeito mútuo & 5 & 9,0 & 1 & 3,03 & 1 & 3,0 & 7 & 9,7 \\
\hline Sedução & - & - & 1 & 3,03 & 1 & 3,0 & 1 & 1,3 \\
\hline Criticar/ensinar/dominar & - & - & 1 & 3,03 & - & - & 3 & 4,7 \\
\hline Interação interindividual & 4 & 7,2 & 1 & 3,03 & 3 & 9,0 & 3 & 4,7 \\
\hline
\end{tabular}

Continua... 
Tabela 3

Continuação

\begin{tabular}{|c|c|c|c|c|c|c|c|c|}
\hline \multirow{2}{*}{ Temas } & \multicolumn{2}{|c|}{$\mathbf{A x A}$} & \multicolumn{2}{|c|}{$\operatorname{AxS}$} & \multicolumn{2}{|c|}{$\mathbf{J x} \mathbf{N J}$} & \multicolumn{2}{|c|}{$\mathbf{A x A}$} \\
\hline & $\mathrm{F}$ & $\%$ & $\mathrm{~F}$ & $\%$ & $\mathrm{~F}$ & $\%$ & $\mathrm{~F}$ & $\%$ \\
\hline \multicolumn{9}{|l|}{ Estilo Expressivo } \\
\hline Cortesia/cumprimento & 11 & 20,0 & 4 & 12,12 & 10 & 30,3 & 25 & 34,7 \\
\hline Gestos/toques & 1 & 1,8 & 1 & 3,03 & - & - & 1 & 1,3 \\
\hline Não sabe/língua diferente & - & - & 3 & 9,09 & - & - & 6 & 8,3 \\
\hline Em árabe & - & - & - & - & - & - & 1 & 1,3 \\
\hline Misturar idiomas & - & - & - & - & - & - & 2 & 2,7 \\
\hline Não responde & - & - & - & - & 2 & 6,0 & 5 & 6,9 \\
\hline Outros & 1 & 1,81 & - & - & - & - & - & - \\
\hline Total & 55 & & 33 & & 33 & & 72 & \\
\hline
\end{tabular}

$\chi^{2}$ (judeus e não judeus) $=52,359 ; \mathrm{gl}=14 ; \mathrm{p}<0,0001$.

Quanto aos países que escolheriam para morar, observamos poucos destaques. Em geral, os subgrupos mencionaram países anglo-americanos $(\mathrm{AxA}=45,4 \% ; \mathrm{AxS}=44,1 \%$; $\mathrm{JxNJ}=43,9 ; \mathrm{NJ}=44,3 \%$ ), seguidos por Israel no caso dos judeus, no que houve maior frequência dos AxA e AxS $(21,8 \%, 20,5 \%$ e $14,6 \%$, respectivamente). Em seguida, os jovens escolheram países europeus (AxA=14,5\%; $\mathrm{AxS}=17,6 \% ; \mathrm{JxNJ}=19,5 \% ; \mathrm{NJ}=\mathrm{NJ}=34,5 \%$ ) e ficar no Brasil $(\mathrm{AxA}=10,9 \% ; \mathrm{AxS}=5,8 \% ; \mathrm{JxNJ}=12,1 \% ; \mathrm{NJ}=13,5 \%)$. Já entre os não judeus, observamos destaque para países europeus latinos e não latinos $(\mathrm{AxA}=5,4 \%$ e 7,2\%; $\mathrm{AxS}=5,8 \%$ e 5,8\%; $\mathrm{JxNJ}=9,7 \%$ e $7,3 \% ; \mathrm{NJ}=18,7 \%$ e $12,7 \%$, respectivamente) e regiões e cidades do Brasil $(\mathrm{AxA}=3,6 ; \mathrm{AxS}=5,8 ; \mathrm{JxNJ}=$ $4,8 \%$; $\mathrm{NJ}=8,8 \%$ ).

Houve um consenso parcial entre AxA e AxS (50,5\% e $46,1 \%$, respectivamente), no sentido de se lembrarem de quase a mesma quantidade de sobrenomes asquenazim, enquanto os JxNJ apresentaram a frequência mais baixa $(36,8 \%)$. Por outro lado, houve uma equiparação entre os três grupos quanto aos sobrenomes sefaradim, cerca de cinco vezes menores que os asquenazim. Os não judeus apresentaram grande percentagem de sobrenomes de origem ibérica $(89,9 \%)$, mas foi praticamente pequena a parte de outras origens europeias, mesmo sendo não judaicas $(2,9 \%)$. Quanto aos números médios de sobrenomes das famílias dos próprios participantes, foram 3,34 (AxA), 3,94 (AxS) e 4,08 (JxNJ), praticamente iguais aos encontrados entre os da escola não judaica $(\mathrm{NJ}=4,29)$. Porém eles foram menores que os obtidos entre estudantes de escolas públicas na Espanha de diferentes origens (Sefaradim, 7,73; Bascos, 6,78; Espanhóis, 5,57) em outra pesquisa (Souza Filho \& Beldarrain-Durandegui, 2008).

Conforme os resultados que obtivemos em termos de tipos de influência social inferida, houve diferenciação entre os grupos tanto dos jovens pertencentes a famílias dentro da comunidade judaica, quanto entre os jovens judeus e não judeus. Como havíamos previsto, os asquenazins-sefaradins tenderam a uma forma de influência baseada em modelos indiretos em que as autoridades familiares procuram mostrar na sua própria conduta individual como se deve agir/ pensar, ao passo que os asquenazins se destacaram em investimento maior na influência baseada em benefícios que eles podem oferecer aos filhos/netos, em aspectos básicos da vida individual. Já a comparação entre judeus e não judeus indicou primeiro a tendência maior dos não judeus em influência familiar, a partir de relações imediatas (relações básicas e interpessoais) que se realizam, vale dizer, com a copresença de ambos os polos da relação (filhos/netos e pais/ avós). Os judeus, por sua vez, tenderam a formas indiretas de influência, a partir de modelos de conduta individuais (indivíduo, valores morais/éticos, vida/morte), além da própria comunidade (grupo cultural) que é vivida/descrita, a partir dos aspectos simultaneamente individuais e grupais face à sociedade, amiúde relacionados à família ampliada dos mesmos. No campo da influência social minoritária, pesquisas recentes indicaram o papel da ambivalência da fonte minoritária, estudada como aspectos positivos e negativos simultâneos comunicados pela mesma, como conteúdos indiretos que incrementam a influência (Mucchi-Faina \& Pagliaro, 2008). Sabemos que a tradição religiosa e o humor judaico apresentam esse tipo de influência, a partir da ambivalência, tal como o argumento paradoxal para convencer ou o humor que "ri de si mesmo".

Portanto, os subgrupos de jovens judeus diferiram quanto a alguns aspectos relacionados ao processo de individuação percebida nos seus familiares. Aqueles, com presença de sefaradins e não judeus, tenderam a enfatizar formação, realização profissional e reconhecimento social, confirmando maior busca de "sucesso", havendo uma forte mobilização, portanto, para a competição social. Já entre os que tinham presença de não judeus, a individuação apareceu relacionada à percepção de familiares entre presença/ausência e exige respeito. O subgrupo asquenazi, enfim, tendeu a enfatizar proteção/cuidado, amizade e realização subjetiva - que são outros tipos de individuação, ainda que não visem, diretamente, à autonomia individual. Enfim, a comparação numérica de lembranças indicou certa tendência de menor frequência dos não judeus, possivelmente em função de uma postura de discrição, a respeito da vida privada manifestada também por um percentual maior de "não respostas" por parte dos mesmos. 
Quanto às possíveis repercussões da vida familiar nas relações interculturais, aqui analisada na autoapresentação para alguém de religião/cultura diferente (budista ou muçulmana), escolha de país para viver e percepção de sobrenomes fora dos da própria família, verificamos que os subgrupos judeus buscavam um possível contato direto com outro grupo étnico/religioso para ressaltar mais essa dimensão, tanto de si mesmo quanto do outro, ao passo que entre os não judeus foi mais frequente a cortesia/cumprimento sem explicitar conteúdos. Ou seja, os não judeus, pertencendo a grupos católicos, majoritários na sociedade, tenderam a apresentar uma forma de autoapresentação mais superficial, tanto de si mesmos quanto em relação ao outro, possivelmente por considerarem que o catolicismo é muito conhecido socialmente, dispensando-os da explicitação da diferença.

Já na escolha de outro país para viver, prevaleceram os países do hemisfério norte entre os grupos, apesar de alguma tendência entre os judeus por Israel e entre os não judeus por países de origem europeia e latina, ambas as preferências relacionadas às suas identificações culturais. Ou seja, a partir dos resultados, é possível afirmar que, embora a globalização possa ter intensificado a influência anglo-americana sobre os grupos que observamos, ela não tem impedido a troca com outras áreas do mundo relacionadas às suas identidades e locais de vida (Hermans \& Dimaggio, 2007).

Enfim, como esperado, os sobrenomes fora da família mais mencionados por judeus foram os do seu grupo, enquanto os sobrenomes mais citados por não judeus foram os de origem ibérica. Tais resultados indicaram que existe certa tendência de superestimar a presença de certos grupos culturais no país em detrimento de outros, conforme a análise de sobrenomes apresentada nos resultados desta pesquisa. Ou seja, alguns sobrenomes de outras identidades culturais foram menos mencionados (como italianos e alemães, por exemplo), as quais podem ser consideradas numericamente minoritárias, ainda que não necessariamente desvalorizadas, merecendo pesquisas ulteriores.

Portanto, as percepções de familiares/grupos tenderam a repercutir simbolicamente na vida intercultural. Ou seja, a identidade étnica, para os judeus, correspondeu a um maior autocentramento grupal. Podemos interpretar no conjunto tais dados, a partir de fatores cognitivos e culturais, tais como a menor experiência/informação/envolvimento a respeito do extragrupo proposto, entre outros. Já os $\mathrm{AxS}$, além de maior frequência de avaliações individuais "cognitivas", apresentaram descentramento familiar (atenção aos processos de formação individual e família ampliada), correspondendo à dispersão entre as várias respostas interculturais, possivelmente propiciadas pelo casamento misto.

Os grupos étnicos minoritários enfrentam, na vida contemporânea, o problema sério da desidentificação dos seus membros, de abandono de práticas culturais e religiosas, de certa amnésia a respeito de sua história, possivelmente intensificada com a globalização (Halas, 2008). Os esforços empreendidos por estes grupos para reverterem estas tendências se refletiram nas palavras dos jovens judeus. Na realidade, a ideia de respeitar o indivíduo na infância, inclusive tolerando até certo ponto a espontaneidade e a expressão livre, é um ingrediente importante para compreender porque os judeus são leais à sua cultura e religião. Ela permite a interiorização de valores e uma base mais sólida de realidade para tratar de problemas ao longo da vida. Sabemos que outros modos de influência são utilizados para realizar uma formação judaica, como aqueles baseados no poder de recompensar e punir que desfrutam autoridades familiares, assim como os modelos de identificação, os conteúdos culturais em si, ficando secundários diante da motivação para realizar um papel social como pai/mãe/filho/neto. Enfim, acreditamos que boa parte da formação da identidade cultural/religiosa judaica esteja relacionada à construção da memória do grupo que tem aspectos coletivos e individuais, como as lembranças comunicadas por meio das respostas dadas ao questionário que aplicamos. Nesse sentido, constatamos entre os jovens judeus uma preocupação com os idosos adoentados e/ou mortos como parte dessa atividade psicossocial grupal importante. É possível que o Holocausto tenha gerado um efeito similar, de busca de memória. Contudo, notamos que houve tendência de concentrar mais lembranças de familiares sobre os pais e avós, resultado similar ao que observamos entre os não judeus, ainda que o volume relativo de respostas tenha sido maior no primeiro grupo.

Encontramos mais traços em comum entre os subgrupos observados (em torno de $45 \%$ ) do que específicos. No âmbito interno, acreditamos que as peculiaridades observadas não prejudicam a convivência dos seus membros, pois todas elas encontram naqueles consensos, parciais ou gerais, e formas de melhor encaminhamento intragrupal. Ou seja, existem tanto unidade quanto diversidade na comunidade judaica observada. Quanto à nostalgia/queixa de familiares ausentes, mais pronunciada entre os oriundos de famílias mistas de judeus/não judeus, pode estar relacionada à ruptura que representou a conversão para o judaísmo por ocasião do casamento. Seriam precisos outros estudos a este respeito no âmbito da sociedade brasileira, na qual ocorre um número surpreendente de miscigenações e rupturas culturais, como elos perdidos e apagamentos, o que poderia ser comparado, por sua vez, ao que aconteceu com outros migrantes como os da Argentina.

\section{Considerações finais}

Enfim, a análise comparativa permitiu-nos inferir que os modelos de influência mais adotados, nos ambientes familiares, foram diferenciados entre os grupos. Ademais, tais modelos tiveram repercussões também diferenciadas nas lembranças dos antepassados, na autoapresentação a um estrangeiro, na escolha dos países que viveriam e na percepção dos sobrenomes existentes no país. Os judeus tenderam, principalmente, à formação/afirmação individual e identitária cultural/ religiosa. Já os não judeus tenderam a lembrar mais aspectos relacionais da família e menor focalização nos aspectos grupais socioculturais tanto de si quanto dos outros. 


\section{Referências}

Friedman, M. L., Friedlander, M. L., \& Blustein, D. L. (2005). Toward an understanding of Jewish identity: A phenomenological study. Journal of Counseling Psychology, 52, 77-83.

Gonçalves, H. S. (2005). Juventude brasileira, entre a tradição e a modernidade. Tempo Social, 17, 207-219.

Goldberg, D. J., \& Rayner, J. D. (1989). The Jewish people: Their history and their religion. Londres: Penguin Books.

Halas, E. (2008). Issues of social memory and their challengers in the global age. Time \& Society, 17, 103118.

Hermans, H. J. M., \& Dimaggio, G. (2007). Self, identity, and globalization in times of uncertainty: A dialogical analysis. Review of General Psychology, 11, 31-61.

Kelman, H. C. (1958). Compliance, identification and internalization: Three processes of attitude change. Journal of Conflict Resolution, 2, 51-60.

Lewin, K. (1948). Resolving social conflicts. Nova York: Harper \& Row.

Maimondes, M. (1956). The guide for the perplexed. New York: Harper \& Row. (Original de 1190)

Moscovici, S. (1979). Psychologie des minorités actives. Paris: P.U.F.

Mucchi-Faina, A., \& Pagliaro, S. (2008). Minority influence: The role of ambivalence toward the source. European Journal of Social Psychology, 38, 612-623.

Novinsky, A. (1992). Cristianos nuevos y judios sefardies en Brasil. In H. Méchoulan (Org.), Los judios de España (pp. 607-624). Valladolid: Trotta.

Peleg-Popko, K., \& Abu-Hanna N. (2003). Cross-cultural and familial differences between Arab and Jewish adolescents in test anxiety. International Journal of Intercultural Relations, 27, 525-541.

Silva Junior, N. G. S., \& Andrade, A. N. (2007). "É melhor pra você!": Normatização social da infância e da família no Brasil. Revista do Departamento Psicologia - UFF, 19, 423-438.

Somech, A. (2000). The independent and the interdependent selves: Different meanings in different cultures. International Journal of Intercultural Relations, 24, 161172.

Souza Filho, E. A., \& Beldarrain-Durandegui, A. (2008). Relações familiares e interculturais na Espanha $e$ Brasil. Rio de Janeiro: Programa de Pós-graduação em Psicologia da UFRJ.

Scliar, M. (1994). Judaísmo: Dispersão e unidade. São Paulo: Ática.

Szymanski, H. (2006). Práticas educativas familiares e o sentido da constituição identitária. Paidéia (Ribeirão Preto), 16, 81-90.
Edson Alves de Souza Filho é Professor Associado do Programa de Pós-graduação em Psicologia da Universidade Federal do Rio de Janeiro.

Angel Beldarrain-Durandegui é Doutor em Ciências Sociais/Psicología Social pela Loughborough University (UK).

Recebido: 10/12/2008

$1^{a}$ revisão: $26 / 06 / 2009$

$2^{a}$ revisão: 22/08/2009

Aceite final: 07/09/2009 